\title{
M. Socolovsky, L. Rasulic, R. Midha, D. Garozzo: Manual of peripheral nerve surgery: from the basics to complex procedures
}

\section{Thieme Verlag, New York, Stuttgart, Delhi, Rio de Janeiro, 2017, 238 pp, 267 figs., 270.0 mm, Softcover (GEB), EUR (D) 149,99, EUR (A) 154,20, CHF 172,00, ISBN: 978-3-13-240955-2}

\author{
Alain G. Graftiaux ${ }^{1} \cdot$ Pierre Kehr $^{1}$
}

Received: 6 April 2018 / Accepted: 20 May 2018 / Published online: 4 June 2018

(c) Springer-Verlag France SAS, part of Springer Nature 2018

This book will be interesting for all the surgeons who are interested in the surgery of the nerves. The authors choose to as well treat the lesions of the nerves of the upper limb, but also the nerve lesions of lower limb and of the face. This book is about varied nerve lesions such as compressions, the wounds, the neurological tumors and pains. It should be noted that the clinical examination is particularly detailed with many photographs as well as the novel methods of exploration by MRI and scans. The various aspects of the nerve lesions are treated in a didactic way and very practical. One will regret in particular during the surgical treatments the absence of the preferred technique of the author and drawings or photographs operational more abundant.

This book is complete, extremely interesting and indeed designed.

\section{Compliance with ethical standards}

Conflict of interest The author(s) declare that they have no competing interests.
Pierre Kehr

Strasbourg, France 